\title{
The Impact of Resource Uncertainty and Intergroup Conflict on Harvesting in the Common-Pool Resource Experiment
}

\author{
Karolina Safarzynska ${ }^{1}$
}

Accepted: 10 November 2017 / Published online: 22 November 2017

(C) The Author(s) 2017. This article is an open access publication

\begin{abstract}
How do resource uncertainty and intergroup conflict affect intragroup cooperation over resources in the common pool dilemmas? Does a danger of sudden resource depletion encourage random acts of violence? There are concerns that climate change will escalate conflicts over, and the scarcity of, renewable resources, which are already under threat or in a state of decline. However, we know surprisingly little about the impact of uncertainty on intergroup conflict over resources. In this paper, we present experimental evidence from a mixed design experiment with two-between-group factors: (1) the presence (or absence) of shocks that can destroy a part of resources; and (2) the availability of intergroup conflict. We find that random shocks encourage resource conservation within groups. The positive impact of resource uncertainty on resource conservation disappears in the presence of conflict. It seems that subjects protect themselves from resource exhaustion in the presence of shocks by engaging in conflict and taking resources from the out-group instead of reducing extraction. In general, conflict promotes intragroup cooperation, but this is conditional on the outcomes of past conflicts. In particular, groups harvest more after wins, and only reduce extraction after losing resources in conflict.
\end{abstract}

Keywords Climate $\cdot$ Conflict $\cdot$ Common-pool resources $\cdot$ Harvesting

\section{Introduction}

One of the biggest environmental problems concerns preventing the deterioration of natural resources. Studies of common-pool resource dilemmas (CPR) analyze harvesting decisions within groups in repeated games with the aim of identifying conditions under which groups

Electronic supplementary material The online version of this article (https://doi.org/10.1007/s10640017-0193-9) contains supplementary material, which is available to authorized users.

$\bowtie$ Karolina Safarzynska

ksafarzynska@wne.uw.edu.pl

1 Faculty of Economic Sciences, Warsaw University, Długa 44/50, 02-241 Warsaw, Poland 
self-organize so as to prevent resource exhaustion (Ostrom et al. 1994; Ostrom 1992, 2006; Sigmund et al. 2010; Janssen et al. 2011). In most studies, group members harvest resources in the absence of any between-group spillovers. However, $85 \%$ of Africa's water resources are composed of large river basins that are shared between several countries (Ashton 2002). Conflicts over water or fishing camps are frequent and are likely to escalate in the future because of climate change (Pomeroy et al. 2007; Mwiturubani 2010; Downing et al. 2014). How does intergroup conflict affect in-group behavior under resource uncertainty? Would a danger of sudden resource depletion encourage random acts of violence? To answer these questions, in this paper, we propose an experimental research design to examine the causal relationships between resource uncertainty, intergroup conflict and intragroup cooperation in the CPRs. Formally, we present experimental evidence from a 2-way mixed design experiment with two-between-group factors: (1) the presence (or absence) of shocks that can destroy a part of resources; and (2) the availability of intergroup conflict.

Our approach is motivated by the fact that the intensity and severity of natural disasters is expected to increase in the forthcoming years due to climate change (IPCC 2007). There are concerns that climate change will escalate conflicts over renewable resources, which are already under threat or in a state of decline. The empirical evidence from 183 preindustrial societies indicates that resource volatility, rather than consistent resource scarcity, makes war between them more likely (Ember and Ember 1992). Also recent studies have shown that climate-related disasters increase the instances of intergroup conflicts (e.g. Harari and La Ferrara 2017), Hsiang et al. (2013) find that changes in climate towards warmer temperatures and more extremes rainfall increase the frequency of intergroup conflict by $14 \%$, while Schleussner et al. (2016) report a coincidence rate of $9 \%$ between armed-conflict and climate-related natural disasters over the period of 1980 and 2010 globally. So far, we know surprisingly little about specific mechanisms through which resource uncertainty affects intergroup conflict over resources and in-group harvesting in CPRs.

The relationship between natural resources and conflict remains a much debated topic in economics (Mildner et al. 2011; Nillesen and Bulte 2014). According to the first view, conflict results from resource scarcities, which leads to unequal resource distribution (Homer-Dixon 1994; 1999). From this perspective, deprived groups are forced to fight over resources for survival. However, there has been little empirical evidence to support this view (De Koning 2007; Mildner et al. 2011). Instead, studies point out increasingly that resource abundance and greed drives conflicts more often than grievance (Collier and Hoeffler 2004). For instance, armed conflicts in many Central and West African countries have been financed with revenues from selling timber, which has been referred to in the literature as "forest wars" (FAO 2005; USAID 2005; De Koning 2007).

In our design, we consider conflict by greed. We model the probability of winning in conflict as proportional to the difference in resources between groups. As a result, groups, which conserve resources, are also more likely to defeat their opponents. The design of our experiment allows us to compare our results to the preceding studies. In particular, research has shown that intergroup conflict increases within-group cooperation in experiments, where conflict is exogenously imposed on group (e.g. Rapoport and Bornstein 1987; Abbink et al. 2012; Cardenas and Mantilla 2015). We take here a different approach and examine the probability that a group would raid another group to take its resources in a controlled laboratory conditions, which allows us to study factors conducive to conflicts. Would the possibility of conflict make subjects conserve resources so as to increases their chances of winning? A combination of "in-group love" and "out-group hate" has been referred to in the literature as parochial altruism (Choi and Bowles 2007). Would it evolve under resource uncertainty? 
Formally, we report the results from a laboratory experiment, where subjects decide how many resources to harvest from a common pool of resources. In the baseline scenario, subjects harvest resources repeatedly within groups from the renewable resource, which re-grows according to the logistic curve. Group members face the temptation to maximize their harvests so as to accumulate more profits. However, if the resource becomes exhausted, everyone in the group loses his/her payoffs. In this context, we study how harvesting is affected by random shocks which diminish resources in the shock treatment. Shocks can be thought of as, for instance, weather shocks or climatic events capable of destroying all, or part of, the common-pool resources. We find that subjects harvest significantly less resources if their group experienced a negative shock to resources in the previous round. This can be explained by the fact that shocks diminishing resources increase the probability of resource collapse, which can only be reduced by groups constraining their harvests.

The probability of resource collapse can be also reduced by 'taking' resources from the out-group. In the conflict treatment, after harvesting decisions, subjects vote on whether to engage in conflict over resources with another group. Conflict occurs only if the majority of members in either group vote for it. Subsequently, one third of the resource is transferred from the losing to the winning group. This can be interpreted as the winning group annexing the land, which is rich in resources, from the losing group. Our theoretical prediction is that groups refrain from conflict in the equilibrium. This relates to the fact that on average groups have nothing to gain from conflict as we set the expected gain from conflict equal to 0 . Yet, we find that conflicts occur frequently. In one-third of cases, conflicts take place almost in every round and are very destructive. In particular, resources are destroyed by repeated attacks by out-group members. The possible explanations behind frequent conflicts are the overestimation of the probability of winning, 'the pleasure of being nasty', moral hazard, or excessive risk-taking. In particular, the results from our experiment indicate that the possibility of conflict under resource uncertainty leads to moral hazard. It seems that groups protect themselves from resource exhaustion in the presence of shocks by taking resources from the out-group instead of reducing extraction.

Our formal approach relates to the theoretical and experimental literature on the effect of environmental uncertainty on the equilibrium outcomes in the common-pool resource games (Budescu et al. 1992, 1995; Rapoport et al. 1993; Biel and Grling 1995; Hine and Gifford 1996; Botelho et al. 2014; Aflaki 2013; Antoniadou et al. 2013; Kimbrough and Wilson 2013; Safarzynska 2013; Blanco et al. 2016a, b). In a standard harvesting set-up, individuals request resources from the common pool [e.g. Rapoport et al. (1993)]. Resources are drawn from a uniform distribution each period. If the sum of individual extractions exceeds the realized size of the resource, the resource is destroyed and players receive nothing. Otherwise, players receive amounts equal to their individual requests. Rapoport and his co-authors show that if the risk associated with the resource size is high enough, this can lead to more consumption. In the discussed setting, the availability of resources in the future is independent of current decisions. Similarly, in the dynamic CPR game by Walker and Gardner (1992), players decide repeatedly on the allocation of a fixed amount of endowment between private activity and investment in the CPR. The probability of the game continuation is a function of aggregate group investment in a given period. The authors show that CPRs are destroyed in all cases, and rather quickly. In Walker and Gardner (1992), similarly to paper by Rapoport et al. (1993), the size of the resource does not dependent on decisions of players in previous rounds.

A number of papers have introduced uncertainty to the public good experiments, where subjects are asked to allocate tokens to the public good, which otherwise they can keep for themselves (Dickinson 1998; Gangadharan and Nemes 2009; Blanco et al. 2015). The number of tokens allocated to the public good is then multiplied by a factor greater than one, 
and distributed among group members. It has been shown that making returns from aggregate group investments uncertain lowers individual contributions to the public good (Dickinson 1998; Gangadharan and Nemes 2009). Blanco et al. (2015, 2016b) use a different setting, where subjects are asked to withdraw funds from the group fund to the private account, instead of contributing to the public good. The authors show that introducing uncertainty over the size of the group fund or the probability of destruction of some funds therein increases appropriation from the group fund. The discussed approaches fail to capture the important aspects of dynamics of renewable resources, like groundwater systems, fisheries, and forests (Botelho et al. 2014). To address this, in our experiment, resources are renewable. As a result, decisions of subjects in the current period affect the renewal rate of resources in the future, harvesting possibilities, as well as the probability of the game continuation. We find that in this setting uncertainty makes subjects conserve resources.

In the design of the conflict scenario, especially when specifying the probability of conflict, we followed the literature on contest games, where the probability of winning is proportional to investments in conflict made by competing groups (see for overviews Garfinkel and Skaperdas 2007; Sheremeta 2017). In a typical contest game, several parties or individuals spend resources to secure a prize for themselves (e.g. Bornstein 2003). If a group wins, the prize is distributed among group members equally, otherwise investments are lost. It has been shown that group competition leads to higher level of cooperation and lower levels of freeriding (Bornstein and Erev 1994; Gunnthorsdottir and Rapoport 2006; Abbink et al. 2010). For instance, Abbink et al. (2010) find that conflict expenditures of groups are substantially larger than those of individuals, and both are above the equilibrium. In this paper, we apply a similar approach to Abbink et al. (2010) setting and extend it to the common-pool resource dilemmas. We find that intergroup cooperation is conditional on the outcomes of past conflicts: subjects reduce their harvests only after losing resources in conflict, but they increase extraction after receiving resources from the out-group. The reminders of this paper is as follows. In Sect. 3, we discuss the experimental design and its theoretical predictions, followed by results in Sect. 4. Section 5 concludes.

\section{Experimental Design and Theoretical Predictions}

In the experiment a total group of 288 students participated in 14 sessions. The experiment was conducted in Warsaw and in Vienna: 186 students were recruited at the University of Warsaw and 102 students at the University of Vienna. There are no significant differences in the gender composition or mean age between two samples. In Poland, 54\% of participants were female with the average age of $24.39( \pm 5.56)$, while in Vienna the corresponding values are $45 \%$ and $25.06( \pm 4.4)$ respectively. Students of economics constitute $48 \%$ t of the Polish sample and $34 \%$ of the Austrian sample. The experiment has four treatments, which can be described by a $2 \times 2$ variation in shock and conflict (see "Supplementary Material" part 2 for instructions). In the baseline treatment, subjects harvest resources repeatedly from the common pool of resources. In the shock treatment, we add the possibility of random shocks, which can destroy a part of resources. In two other treatments, i.e. in conflict and 'conflict and shock' treatments, subjects after harvesting vote for intergroup conflict. In the 'conflict and shock' treatment, the availability of conflict and the possibility of shocks are combined. The experiment was programmed and conducted with the software z-TREE (Fischbacher 2007). 
During each session, students were divided into 8 groups (of three persons each). Afterwards, groups were matched into 4 pairs, to which we refer to as partner groups. The reason behind matching groups in pairs is that in the conflict treatment, the probability of winning depends on the difference in resources between groups. As a consequence, groups observe resources in the partner group before deciding on whether to engage in conflict. Resources and their extraction in the partner group can affect in-group harvesting. Therefore, we matched groups in pairs in all treatments, i.e. also in the absence of conflict, so as to create exactly the same 'basic' conditions in all treatments. In other words, subjects could observe resources in their own group and in the partner group in all treatments.

In Warsaw, each treatment was conducted in two separate sessions, with the exception to the shock treatment, which was conducted in three sessions, because of a low show-up rate during earlier sessions. In Vienna, each treatment was conducted in a single session with the exception of the conflict treatment. We report results from 5 instead of 4 partner groups from two separate sessions in Vienna. In Warsaw, due to a low show-up during one of the 'conflict and shock' sessions, we report results only from 3 partner groups. Subjects earned on average about $€ 10.39$ per experiment in Vienna and PLN 42.43 (€ 9.6) in Warsaw.

If a group runs out of resources, subjects lose all their payoffs accumulated up to the moment of resource exhaustion. This creates a strong incentive to conserve resources. We introduced this assumption to prevent the game to come to end too quickly so as to be able to study how conflict unfolds over time. In particular, in CPR experiments, subjects, who are allowed to keep money earned until the moment of resource exhaustion, overharvest resources often in early stages of the experiment, unless punishment, communication or monitoring are introduced (Janssen 2010). This is consistent with predictions of Hardin (1968), who argues that in the absence of external authority, overharvesting of CPRs and "the tragedy of the commons" are inevitable. Regardless of the outcome of the second part of the experiment, students kept a show-up fee (€1.25 in Poland and $€ 2$ in Austria), as well as money earned in the pre-experimental questionnaire (between $€ 1$ and 7.5). The pre-experimental questionnaire includes: the IQ test; trust and dictator games; and the risk elicitation task. In the dictator game, subjects are asked to split $€ 1$ between themselves and another (anonymous) player in the room (see "Supplementary Material" part 3 for the pre-experimental questionnaire). In the trust game, players are asked to split $€ 1$, after being informed that the experimenter will double the amount sent to another player, while the receiver will have a chance to give them some money back. To measure risk preferences, we ask subjects how much of $€ 1$, they are willing to invest in a risky project. The amount invested is tripled with probability $40 \%$ or lost with probability $60 \%$. There were no statistically significant differences in the outcomes of pre-experimental questionnaire between two countries. However, we find that Polish students are more risk-seeking compared to Austrian students. The difference in risk-seeking has been statistically significant, according to the Mann-Whitney test ( $p<0.001)$.

In each session, participants were randomly seated in front of computers with partitions between them. The identities of group members were never revealed to participants. Each session was divided into two parts. In the first part, students were given the opportunity to learn dynamics of the game in 10 rounds of training of the baseline treatment. The rounds of training were followed by the actual experiment, which varied across the four treatments.

During the rounds of training, students were matched in groups of three persons. Groups were not matched in pairs in this part of the experiment. Each group had access to its own renewable resource. Participants were re-matched after training to form new groups. To account for created this way possible dependencies in behavior, we control for outcomes of training in the statistical analysis. During the rounds of training, all students played the baseline game, while the actual experiment involved additional elements, namely: random 
shocks destroying resources; intergroup conflict; or their mixture (Table 1 summarizes different treatments).

In the second part, the actual experiment lasted for 41 periods. Subjects were not informed about the exact number of rounds, only that the experiment would not exceed in total 2 hours. This way we avoided the end-of-round effect, likely to occur in case the number of rounds and their length are known in advance to participants (Janssen 2010). The condition of infinitely repeated game is often induced in the lab by having a random continuation rule: after each round the computer decides whether to finish the repeated game. However, introducing the continuation probability, which stops the game at any time, would prevent us from assessing how long it takes for groups to exhaust resources.

\subsection{Baseline Treatment}

In the baseline treatment, subjects decide how many resources to harvest from the common pool of resources each period. The initial level of resources is equal to 45 in each group. Afterwards resources are diminished by the total harvest $X_{t}$, which are equal to the sum of the individual extractions $X_{t}=\sum_{i} x_{i t}$, and re-grow according to the logistic equation: $R_{t+1}=R_{t}+\dot{R}_{t}-X_{t}=R_{t}+r R_{t}\left(1-R_{t} / K\right)-X_{t}$, where $0<\mathrm{r}<1$ is the intrinsic growth rate of resources; $K$ is its carrying capacity; and $\dot{R}_{t}=r R_{t}\left(1-R_{t} / K\right)$ captures the natural growth or regeneration of resources. In the experiment, we use parameters equal: $r=0.1$, $K=80$, and $R_{0}=45$. Subjects could observe the renewal rate of resources as well as harvesting choices of other group members, appearing in a random order on the screen after each round. This meant, however, that they could not track who harvested how much over time.

The social optimum requires to sustain resources at half of their carrying capacity $(80 / 2=40)$, while harvesting the renewal rate of resources, equals to 2 . In the equilibrium, we expect groups to harvest the renewal rate of resources ( $\mathrm{rR} / \mathrm{K})$, thus $2 / 3$ tokens per person. This in turn implies that the socially optimal fraction of harvested resources equals $(2 / 3) / 40=0.02$. Overall the model predicts the tragedy of the commons, i.e. that groups will harvest above the social optimum of $0.02<0.06$ (see eq. (11) in "Supplementary Material" part 1). ${ }^{1}$ In "Supplementary Material" part 1, we discuss the transition path to the steady-state solution for self-interested profit-maximizing agents.

\subsection{Shock Treatment}

In the shock treatment, a shock can diminish a fraction of resources $0<\theta_{t}<1$ in each period. A shock $z_{t}$ is drawn from the uniform distribution $\mathrm{U}(0.5,1.5)$ with a probability of 0.33 . As a result, the fraction of resources destroyed by a shock is equal to $\theta_{t}=z_{t} / R_{t}$ with $0<\theta_{t}<1$. If shock $z_{t}$ exceeds the resource, the game comes to an end. We consider only negative shocks, which diminish resources. This is because of the fact that in the presence of positive events, resource conservation is not necessary to prevent the collapse of a group. In the shock treatment, the resource follows the modified logistic curve: $R_{t+1}=\left(1-\theta_{t}\right)\left(R_{t}+r R_{t}(1-\right.$ $\left.\left.R_{t} / K\right)\right)-X_{t}$. Information about whether a shock has destroyed part of resources was revealed to students after harvesting decisions. We expect that shocks encourage resource conservation, thus that a fraction of harvested resources will be lower in the shock treatment compared to the baseline (see "Supplementary Material" part 1 for the derivation of equilibrium predictions):

1 This value is computed for the discount rate, which equals 0.99 . The smaller the discount rate is, the larger the fraction of resources harvested in the equilibrium is expected. 


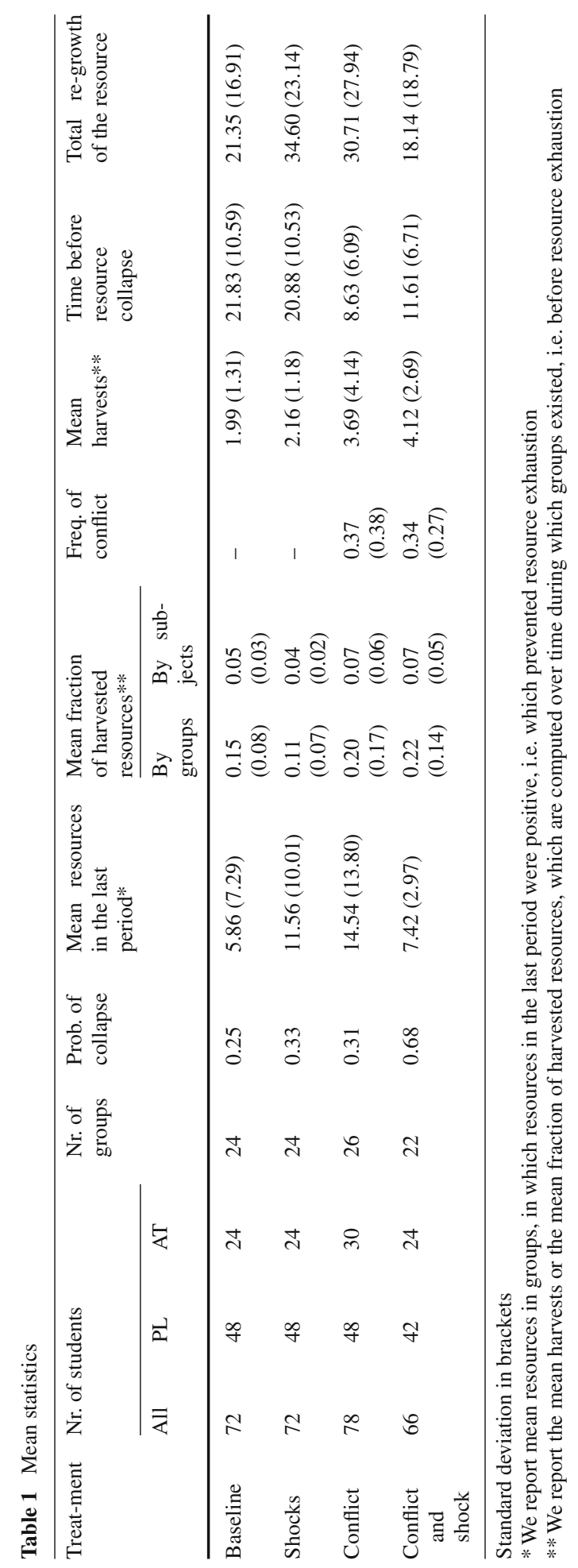




$$
\left(X^{*} / R^{*}\right)_{\text {baseline }}=\frac{1-\beta p(1-r)}{2 \beta p}>\left(X^{*} / R^{*}\right)_{\text {shocks }}=\frac{1-\beta p(1-r+r \theta+\theta)}{2 \beta p},
$$

where $\beta$ is the discount rate. According to the right-hand side equation above, the expected fraction of harvested resources in the equilibrium decreases with the realized size of a shock.

\subsection{Intergroup Conflict}

In the conflict treatment, after harvesting decisions, subjects could decide whether they would like to engage in conflict with the partner group. The conflict occurs if the majority of group members vote for conflict. The probability that group $i$ wins resources from group $j$ at time $t$ is equal to: $R_{i t} /\left(R_{i t}+R_{j t}\right)$. In case a group lost in conflict, one third of its resource is subtracted from group's common pool, and it augments the resource in the partner group. Students were informed about the probability of winning, the expected gain and loss due to conflict before voting.

We expect that a rational, i.e. self-interested payoff-maximizing, risk-averse agent would never engage in conflict. In our experimental design, a group with resources equal $R_{t}$ can win one third of partner group's resources $Z_{t}$ with the probability $R_{t} / R_{t}+Z_{t}$, and lose one third of its resources with the probability $Z_{t} / R_{t}+Z_{t}$. This implies that the expected benefit from engaging in conflict is zero: $1 / 3 Z_{t} \frac{R_{t}}{R_{t}+Z_{t}}-1 / 3 R_{t} \frac{Z_{t}}{R_{t}+Z_{t}}=0$, making risk-averse agents reluctant to engage in conflict. For eliciting risk preferences, we use the method by Gneezy and Potters (1997). In particular, we asked participants before the experiment how much of $€ 1$, she/he would like to invest in a risky option and how much to keep. The amount invested is multiplied by 3 with probability $40 \%$ and it is lost with probability $60 \%$. The money not invested are kept by subjects. Theoretical predictions indicate that a risk-neutral or risk-seeking person should invest $€ 1$, while risk-averse individuals less than the total amount. We find that only 21 out of 288 participants invested $€ 1$. This indicates that $93 \%$ of remaining participants exhibit a different degree of risk-aversion. As a result, unless subjects overestimate the probability of winning, conflict should not occur in the equilibrium.

In "Supplementary Material" part 1 (section 1.2), we show that in case a group wins resources in conflict, its members are expected to harvest a larger fraction of resources compared to the baseline. The fraction of harvested resources increases with the size of the resource received from the partner group. For instance, in case a group received 3.76 units of resources, which constitutes the mean value of a resource transfer due to conflict in our experiment, the expected fraction of harvested resources is 0.16 , using parameter values as employed in the experiment.

\section{4 'Conflict and Shock' Treatment}

In the 'conflict and shock' treatment, we combine the availability of conflict with the possibility of shocks. The information, whether the shock has destroyed part of the resource, was revealed to subjects after harvesting and voting decisions, thus just before harvesting in the next round. In this context, we examine if shocks promote resource conservation or encourage random acts of violence. We also study if subjects reduce their extraction so as to increase the probability of winning in conflict, and how conflict affects in-group behavior.

\section{Results and Discussion}

Figure 2 summarizes mean resources per treatment in each period. Two observations seem noteworthy. First, most groups have significantly diminished resources during the first 5 
Table $2 \mathrm{~F}(1,47)$-statistics indicating whether differences in the mean fraction of resources harvested over time between each pair of treatments are statistically significant

\begin{tabular}{llll}
\hline & Shocks & Conflict & Conflict and shock \\
\hline Baseline & $3.94^{* *}$ & 1.56 & $3.16^{*}$ \\
Shocks & & $6.30^{* *}$ & $9.58^{* * *}$ \\
Conflict & & 0.15 \\
\hline
\end{tabular}

*** Iindicates variable significant at 0.01 level, ** at 0.05 and $*$ at 0.1 level

Table $3 \mathrm{~F}(1,47)$-statistics indicating whether differences in resources in the last round between each pair of treatments are statistically significant

\begin{tabular}{llll}
\hline & Shocks & Conflict & Conflict and shock \\
\hline Baseline & $2.89^{*}$ & $4.41^{* *}$ & 0.5 \\
Shocks & & 0.41 & 1.83 \\
Conflict & & & $3.34 * * *$
\end{tabular}

*** Indicates variable significant at 0.01 level, $* *$ at 0.05 and $*$ at 0.1 level

periods. Only one group in the shock treatment and one in the conflict treatment succeeded to maintain resources close to the social optimum over time (see Figure 4 in "Supplementary Material" part 1). Second, mean resources per treatment are larger in the conflict treatment and in the shock treatment compared to the baseline. We will study to what extent resource conservation is behind differences in resources between these treatments.

Table 1 reports mean statistics from different treatments. Results in Table 1 confirm that mean resources in the last period are larger in the conflict treatment and the shock treatment compared to the baseline. To assess if differences in resources in the last period between each pair of treatments are statistically significant, we regress dummies corresponding to different treatments on resources in the last period, with no constant and error terms clustered on the partner group level. Subsequently, we test whether coefficients corresponding to different treatment dummies are significantly different from each other for each pair of treatments. Table 3 summarizes corresponding F-statistics ${ }^{2}$. Analogously, Table 2 examines statistically significant differences in mean fractions of harvested resources over time, and Fig. 1c in mean harvests between each pair of treatments (Table 4).

Results in Table 1 indicate that mean harvests (as a fraction of resources) are larger in conflict and 'conflict and shock' treatments compared to the baseline, followed by the shock treatment. In the baseline, groups harvest on average 0.15 of resources, which is three times above the optimal extraction. In turn, in the conflict treatment, groups harvest on average 0.20 of resources, which also exceeds our expectations (0.16). Thus, mean resources in the conflict treatment larger than resources in the baseline cannot be explained by subjects conserving resources, but rather by successful groups annexing resources from the defeated groups. On the other hand, we find that under resource uncertainty subjects harvest significantly less resources compared to the baseline, which we discuss in detail in Sect. 3.1. In Sect. 3.2, we study factors conducive to conflicts.

2 Because of re-shuffling group compositions after the rounds of training, we cannot conduct non-parametric tests. 


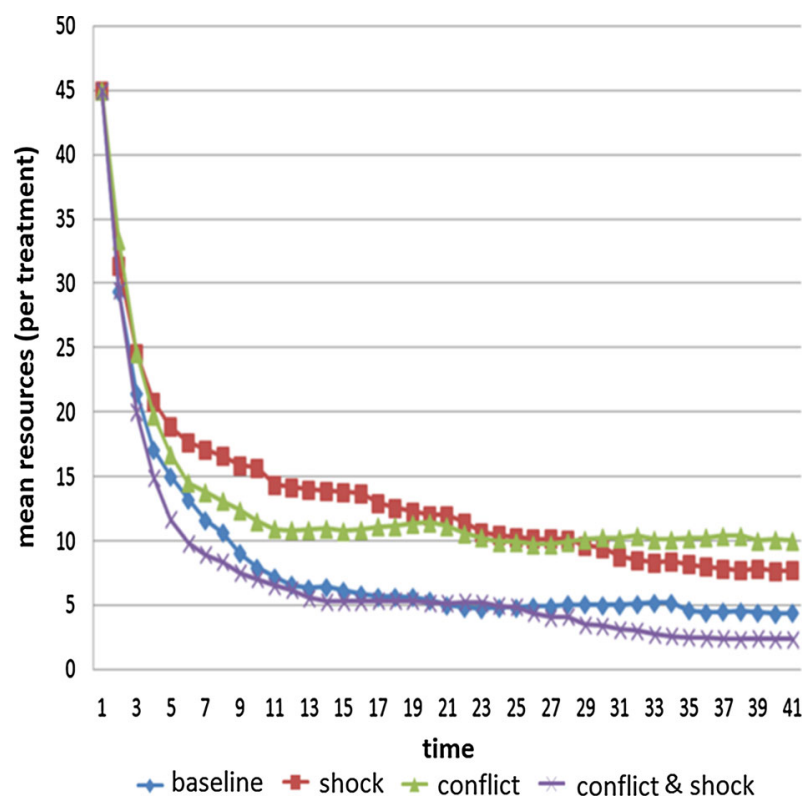

Fig. 1 Mean resources per treatment

Table $4 \mathrm{~F}(1,47)$-statistics indicating whether differences in mean harvests between each pair of treatments are statistically significant

\begin{tabular}{llcc}
\hline & Shocks & Conflict & Conflict and shock \\
\hline Baseline & 0.25 & $4.76^{* *}$ & $11.92 * * *$ \\
Shocks & & $3.95^{* *}$ & $10.50 * * *$ \\
Conflict & & & 0.22 \\
\hline
\end{tabular}

*** Indicates variable significant at 0.01 level, $* *$ at 0.05 and $*$ at 0.1 level

\subsection{The Impact of Shocks and Conflict on Intragroup Cooperation}

In this section, we study how random shocks and the possibility of conflict affect intragroup cooperation. Table 5 presents the results from panel regressions using the pooled data from all treatments with the dependent variable computed as a fraction of resources harvested by subjects. We cluster errors at the session level. The Hausman test indicates that the fixedeffects model is preferable over random-effect regressions $($ Chi2 $(6)=21.012)$. However, the former model does not allow to study the impact of time-invariant variables, so we report the results from random-effect (Models 1-4) and fixed-effect models (Model 6). Models 3 and 4 present the results from regressions run on the subset of data from selected treatments. In Model 5, we introduce AR(1) disturbances to control for serial correlation. In particular, the Wooldridge test indicates that our data suffers from this problem $(\mathrm{F}(1287)=39.46)$. However, the model does not allow to cluster errors on the session level. The results gathered in Table 5 show that our findings are robust to a variety of estimation techniques.

We add as independent variables, in order to control for possible dependencies created due to re-shuffling after the trial period: (1) the dummy indicating if a group, to which a subject 


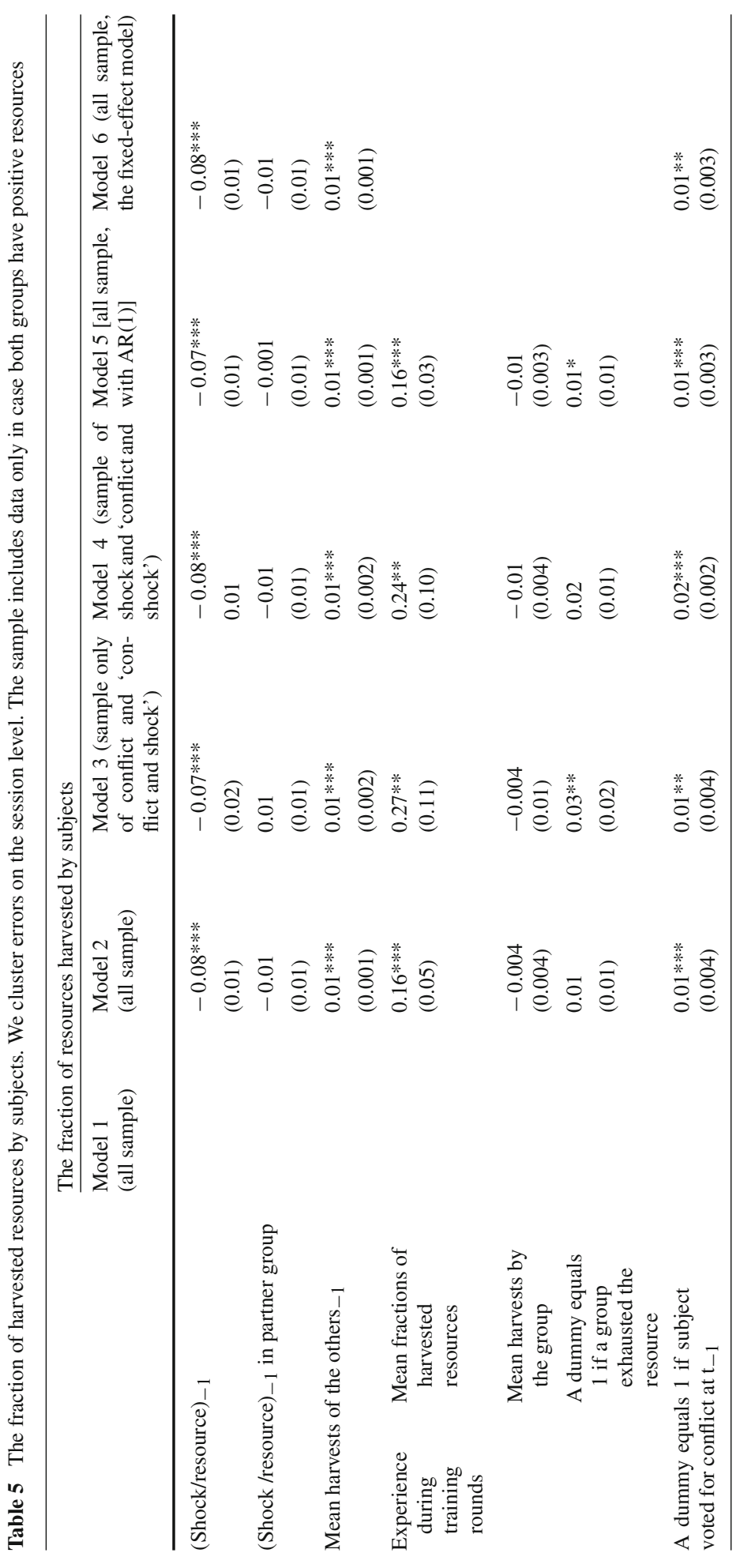




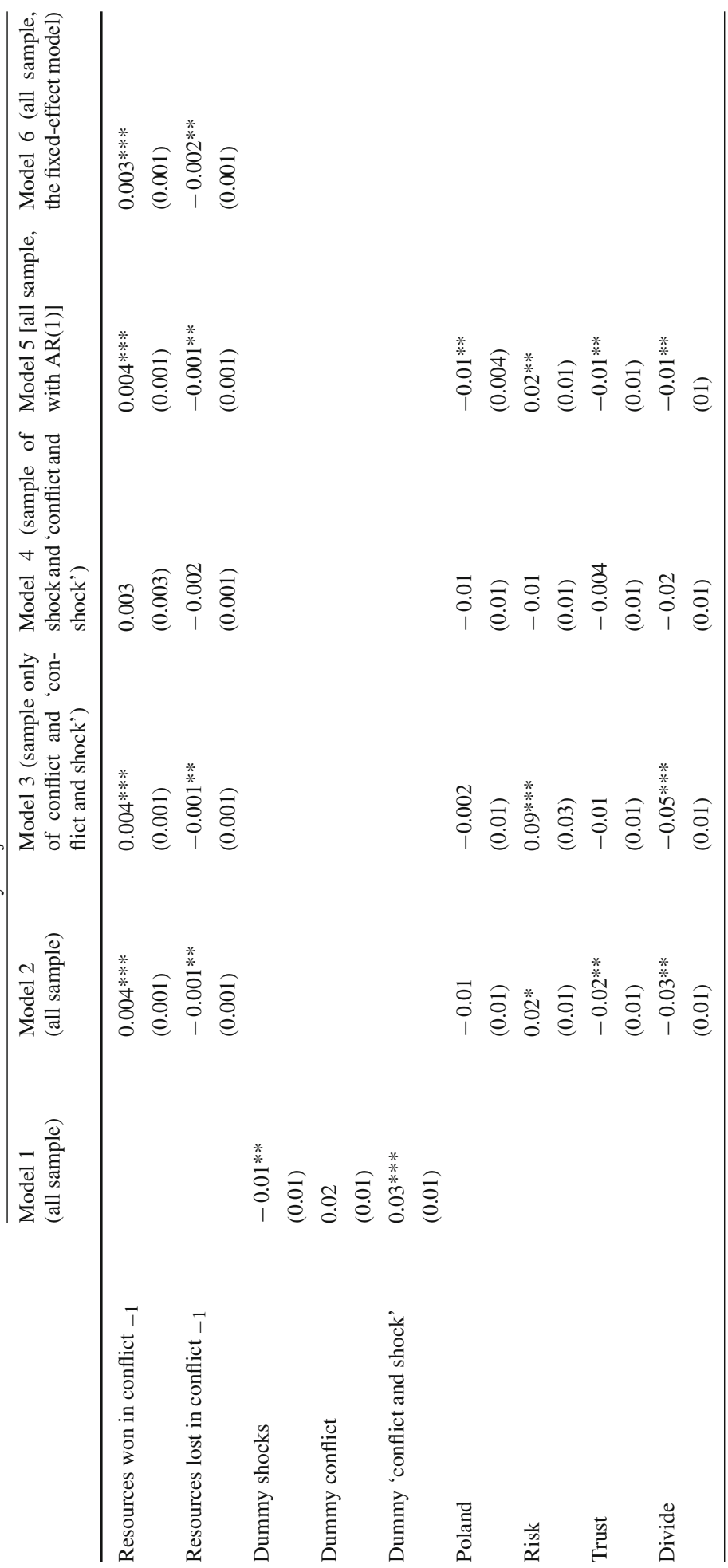




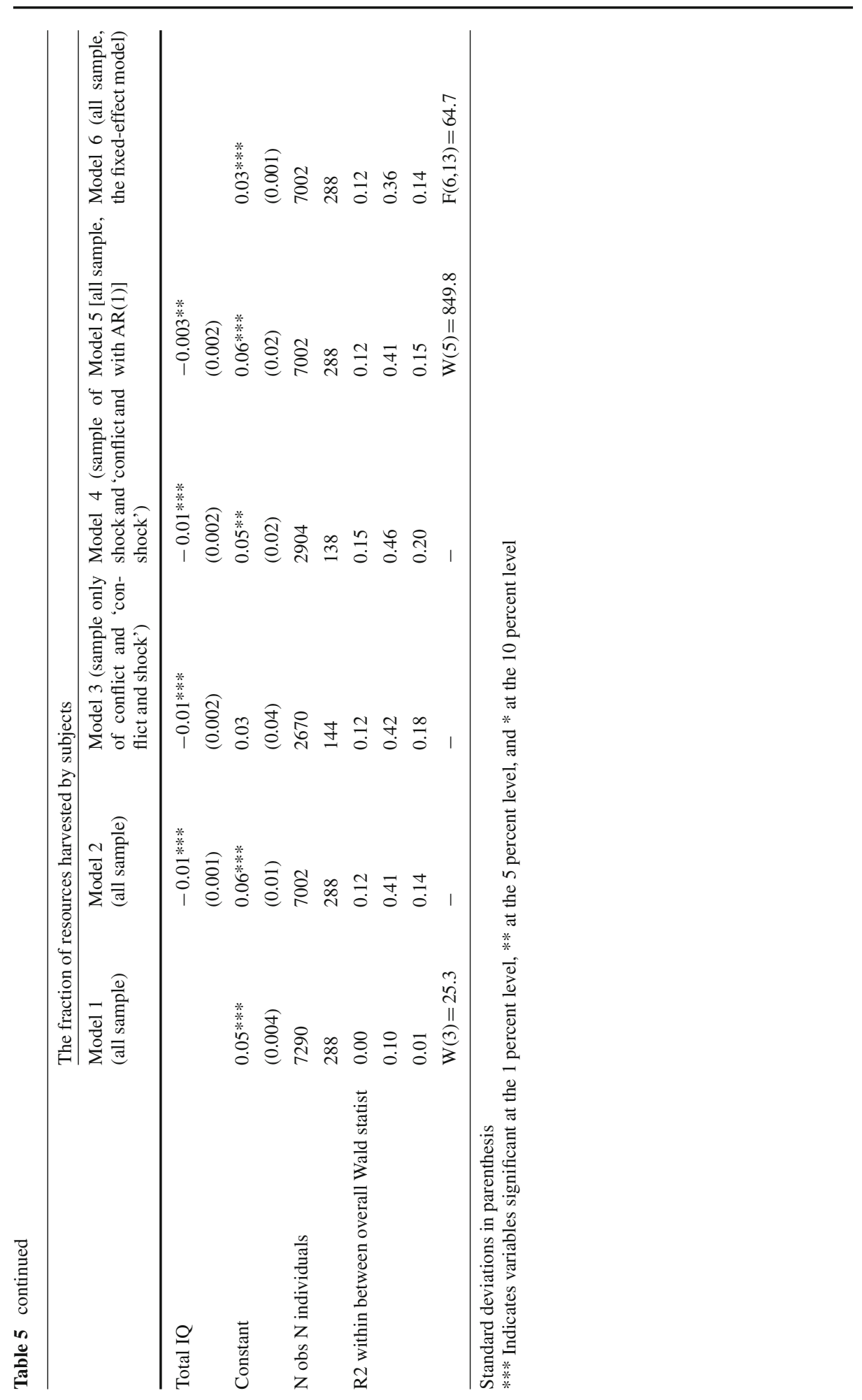


belonged during the rounds of training, prevented resource exhaustion; (2) mean harvests by the training group over 10 periods; and (3) the mean fraction of resources harvested during the rounds of training by each subject. We find that mean harvests during training by individuals as well as groups are statistically significant in explaining subjects' behavior in the actual experiment. As a result, subjects, who overharvested resources during the rounds of training, were more likely to do so as well during the actual experiment.

In addition, we include into regressions dummies: indicating if conflict, shocks or their interaction are allowed; and a dummy equals 1 if a student came from a Polish sample and 0 if she took part in an experiment conducted in Austria. Other dependent variables are: a lagged value of the fraction of resources destroyed by shocks in own group and in the partner group; a transfer of resources in case a group won resources; resources lost due to conflict; and mean harvests by other group members. As additional control variables, we include also outcomes of the trust and dictator game preceding the experiment. In particular, variables 'trust' and 'divide' measure a fraction of 1 Euro, which subjects are willing to give to another person in the dictator and trust games respectively (see "Supplementary Material" part 3 for the pre-experimental questionnaire). 'Risk' indicates a fraction of $€ 1$, which subjects are willing to invest in the risky project, while total IQ measures the number of correct answers in the cognitive test. We find that more altruistic participants, who share a larger fraction of $€ 1$ Euro with another person, are also more likely to conserve resources. In addition, subjects scoring higher on the cognitive test tend to harvest less resources, while risk-seeking leads to overharvesting. These results are statistically significant in most regressions in Table 5.

The results in Table 5 suggest dependencies in behaviors of in-group members. In particular, mean harvests by the others at $\mathrm{t}-1$ have a positive and significant impact on the fraction of harvested resources. This provides some explanation behind the depletion of resources in most groups: subjects adjust their extraction levels to harvests of the others so as not to fall behind them, which leads to a vicious circle of the increasing exploitation of natural resources and their diminishing stocks. Adjusting own harvests to extraction levels of other peers can be indicative of inequity aversion. Falk et al. (2002) show that a simple model of fairness can explain many stylized facts of common-pool resource experiments. The authors argue that subjects are likely to act conditionally on what other subjects do: they conserve resources only if other group members do the same.

\section{Result 1 Shocks significantly decrease extraction and increase conservation with respect to the baseline.}

How does resource uncertainty affect in-group harvesting? Would more severe shocks to resources reduce extraction? Table 1 indicates that the fraction of resources harvested in the shock treatment is significantly lower compared to the baseline. This result cannot be explained by subjects having a lower harvesting rate with lower levels of the resource, as mean resources in the shock treatment are statistically significantly larger compared to the baseline, despite of being diminished by random shocks (Tables 1 and 2). Moreover, the total re-growth of resources is greater in the shock treatment than in the baseline (last column of Table 1). This would not be possible if groups have not reduced their harvests so as to allow the resource to renew itself after shocks.

Results in Table 5 confirm that subjects harvest a significantly less resources in the presence of shocks. In favor of this, the treatment dummy 'shocks' has a negative and significant impact on the fraction of harvested resources in Model 1. In addition, the evidence indicates that the more severe shocks in the previous round encourage resource conservation. In particular, the lagged value of the fraction of resources destroyed by shocks has a negative and 
statistically significant impact on individual harvests (Models 2-6 in Table 5). This confirms our theoretical predictions that resource uncertainty promotes resource conservation. In turn, shocks to resources of the partner group have no statistically significant impact on the fraction of resources harvested by group members.

Result 2 The possibility of conflict itself does not significantly modify extraction. However, if a group won resources in conflict, group members are likely to overharvest resources in the next round. Subjects reduce harvests only after losing part of resources in conflict.

The evidence in Table 1 shows that the mean fraction of resources harvested over time in the conflict treatment is larger than in the baseline $(0.2>0.15)$, yet this difference is statistically insignificant (Table 3). The results in Table 5 support this. In particular, the coefficient corresponding to the 'conflict' treatment dummy is positive, but statistically insignificant in explaining the fraction of harvested resources (Model 1). This may be explained by the fact that winning resources makes subjects harvest a significantly larger fraction of resources, while losing resources in conflict has an opposite effect on harvesting (Models 2-6). Both effects are statistically significant, whereas the opposite impacts of wins and losses on individual harvests cancel each other out.

Result 3 Shocks combined with the potential for conflict increase significantly extraction with respect to the baseline as well as to the shock treatment, inducing the highest likelihood of exhaustion in the 'conflict and shock' treatment.

The mean fraction of harvested resources is significantly lower in the shock treatment compared to the baseline treatment. However, the potential for conflict makes the positive impact of uncertainty on resource conservation disappear in the presence of shocks. Groups harvest a significantly larger fraction of resources in the 'conflict and shock' treatment compared to the shock treatment as well as to the baseline (Table 1 and Model 1 in Table 5). As a result, the probability of resource exhaustion is the highest in the 'conflict and shock' treatment compared to all other options (Table 1). This indicates that group members do not reduce their extractions, which is necessary to prevent resource collapse in the presence of shocks.

\subsection{Factors Conducive to Conflicts in the Presence and Absence of Shocks}

In the conflict treatment, subjects vote if they would like to engage in conflict with the partner group. However, only one pair of groups (out of 24 pairs) in the conflict treatment and one pair of groups in the 'conflict and shock' treatment abstained from any conflict whatsoever, confirming our theoretical predictions. In most cases, groups engaged in conflicts sporadically over the entire experiment. Figure $2 \mathrm{a}$ summarizes the number of conflicts per treatment in each period, while Fig. 2b depicts the corresponding mean values of resources transferred between groups because of conflict. We expected that risk-averse individuals would refrain from conflict in the equilibrium. However, we find that in $33 \%$ of conflicts, groups engaged in conflict frequently, where one group attacked the partner group repeatedly until its collapse. We observe that groups voted for conflict in the 'destructive scenario' even if the resource in the partner group was on the verge of collapse, and the potential gain from conflict was negligible.

What are the factors conducive to conflict? Table 6 summarizes results from the mixedlevel logit panel regressions with the dependent variable equals 1 if a subject voted for conflict and 0 otherwise. In Models 1-7, error terms are nested within groups, then within partner groups, and finally within sessions. We included as independent variables: resources won 


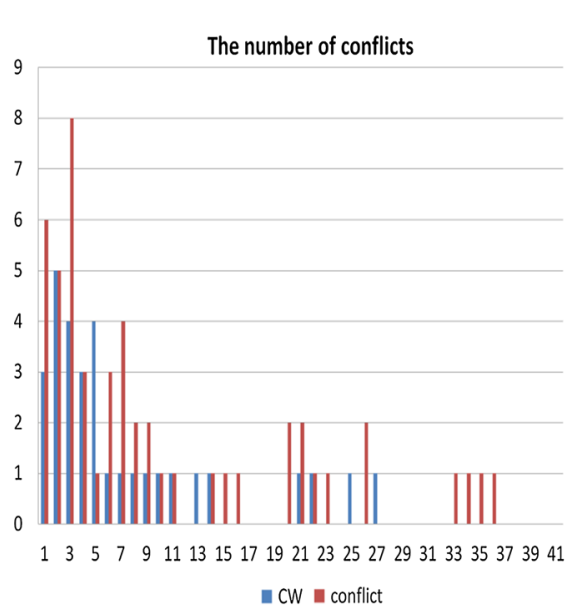

(a)

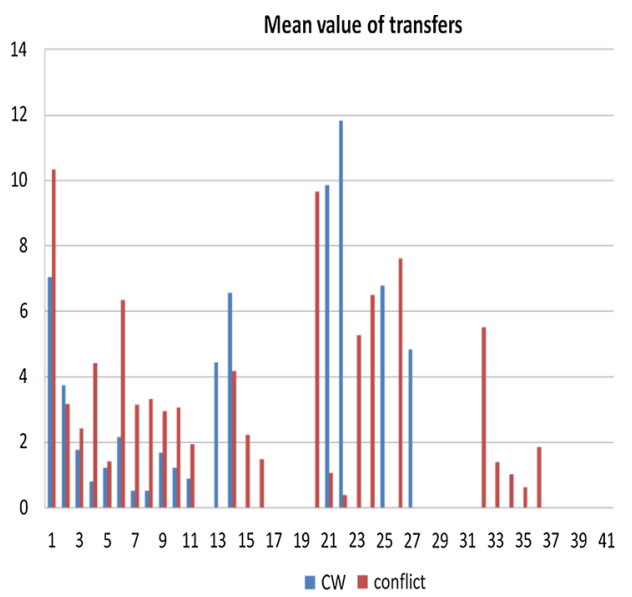

(b)

Fig. 2 The frequency of conflicts over time. a The number of conflicts per treatment. b Mean value of transfers due to conflict

and lost in conflict at $\mathrm{t}-1$; a lagged value of a fraction of harvested resources by subjects, or total payoffs, indicating subjects' harvests accumulated over time; the difference in own resources and resources in the partner group at $\mathrm{t}-1$ if the difference was positive; a variable capturing the difference in resources between groups (its absolute value) if the difference was negative; shocks to own and partner group's resources or fractions of resources destroyed by shocks in both groups; a dummy indicating if an attack at $t-1$ was initiated by in-group members; an additional dummy capturing if a group was attacked by the partner group; and a set of control variables measuring personal characteristics of subjects as in regressions in Table 5 .

\section{Result 4 Resource uncertainty makes conflict more likely.}

The probability of conflict was $37 \%$ in the conflict treatment and $33 \%$ in the 'conflict and shock' treatment (Table 1), yet this difference is statistically insignificant. Figure 3 presents the frequency distribution of the number of conflicts in both treatment. It becomes apparent that the high mean probability of conflict in the conflict treatment is driven by two outliers: two pairs of groups, which engaged in conflict 9 and 15 times respectively. In turn, instances of conflicts occurring less than 6 times are more frequent in the 'conflict and shock' compared to conflict treatment. Moreover, having a closer look at the data reveals that the median probability of conflict is 0.33 in the 'conflict and shock' treatment, and 0.25 in the conflict treatment, indicating that conflict is more likely under resource uncertainty.

After being hit by more severe shocks, subjects are less likely to vote for conflict. The variable shock to resources at time $t$ has a negative and statistically significant impact on the probability of conflict in Models 2 and 5 (Table 6). Surprisingly, the size of a shock in the partner group is insignificant in explaining the probability of conflict (Models 2 and 5). However, subjects are more likely to opt for conflict, the larger the share of resources has been destroyed by shocks in the partner group in past rounds (Models 3 and 6). Thus, the relative size of a shock, and not its absolute value, matters, suggesting that factors that determine relative resources between groups influence the probability of conflict. There is one exception to this rule: groups do not attack the out-group, which resources have been 


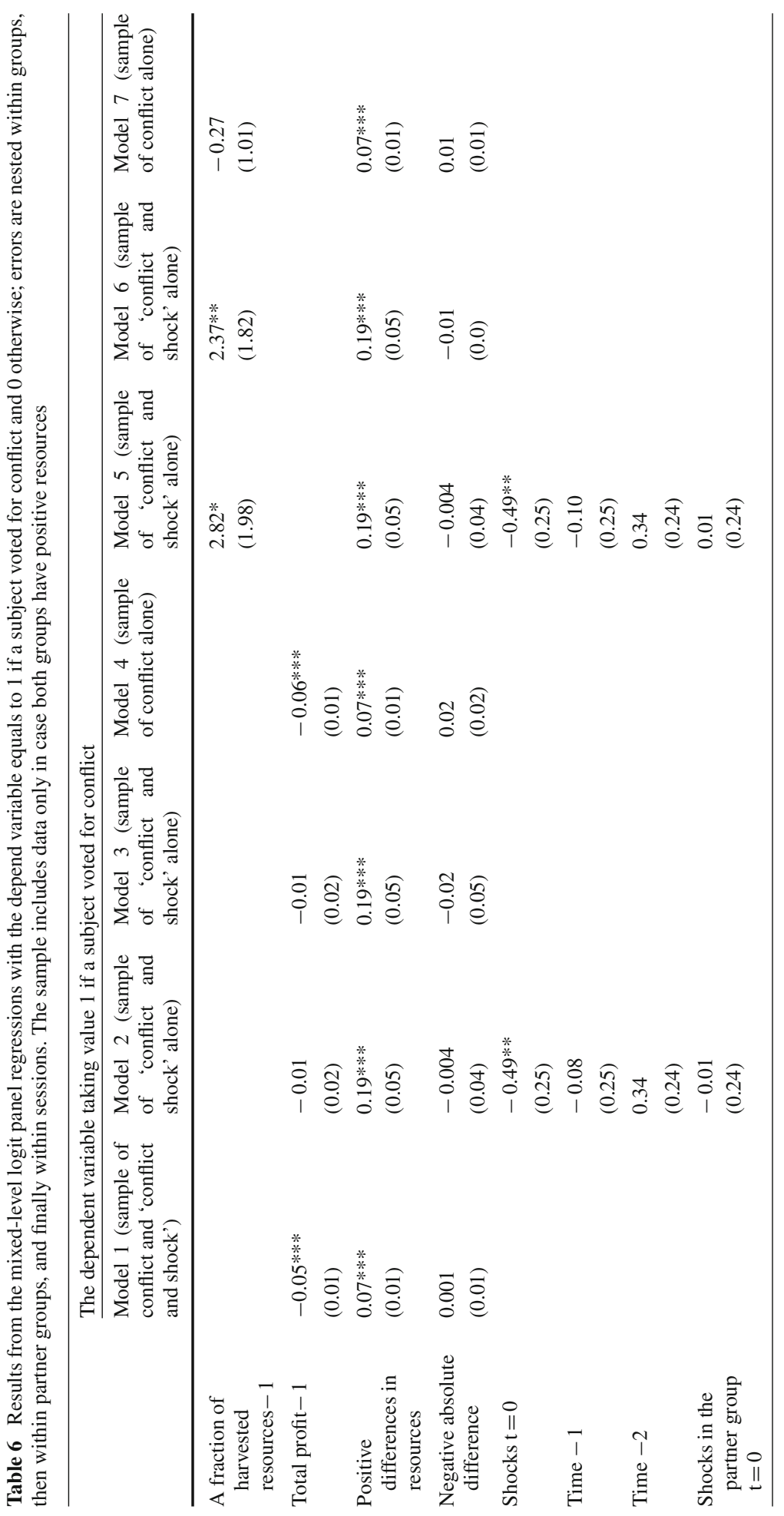




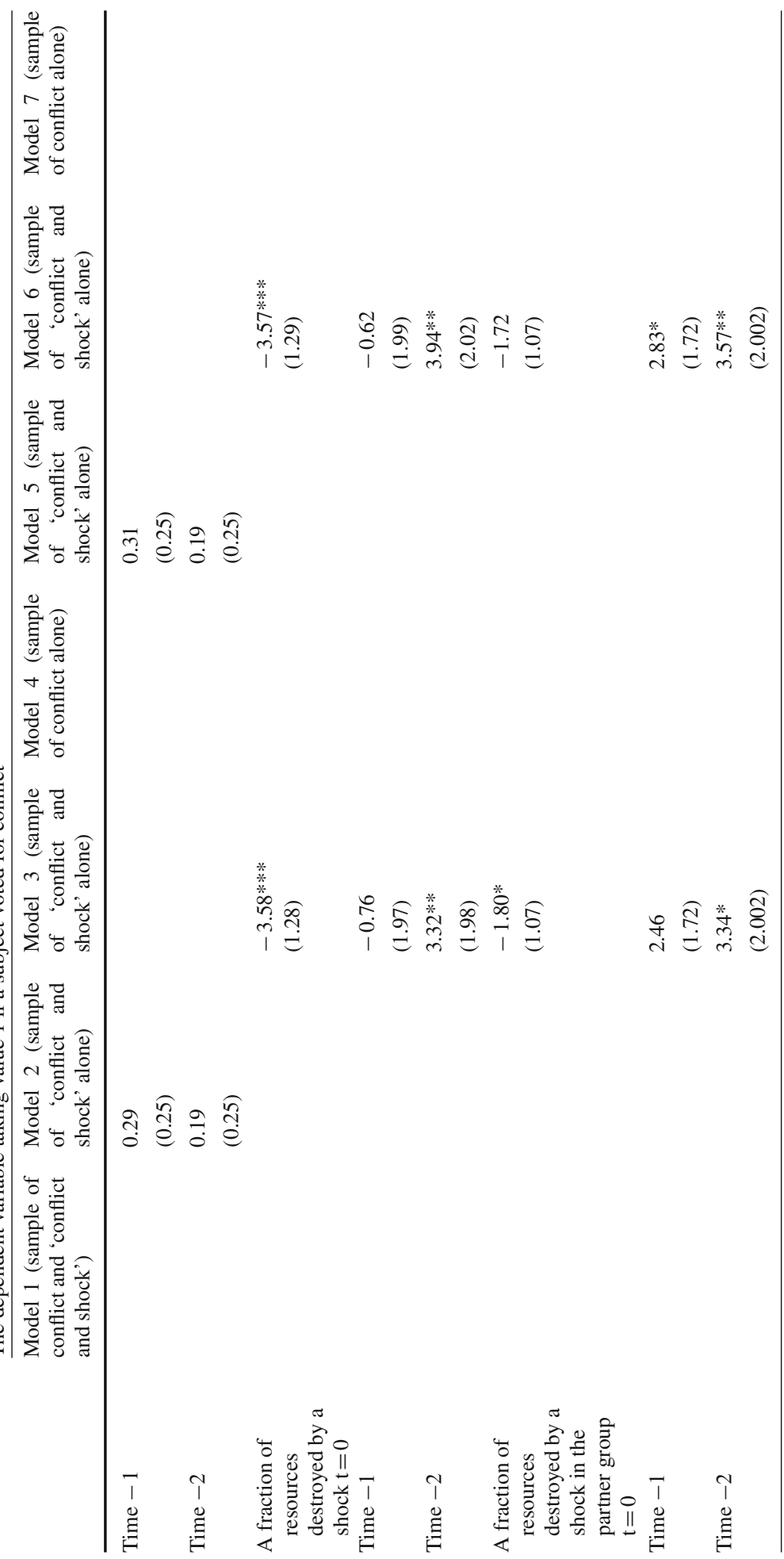




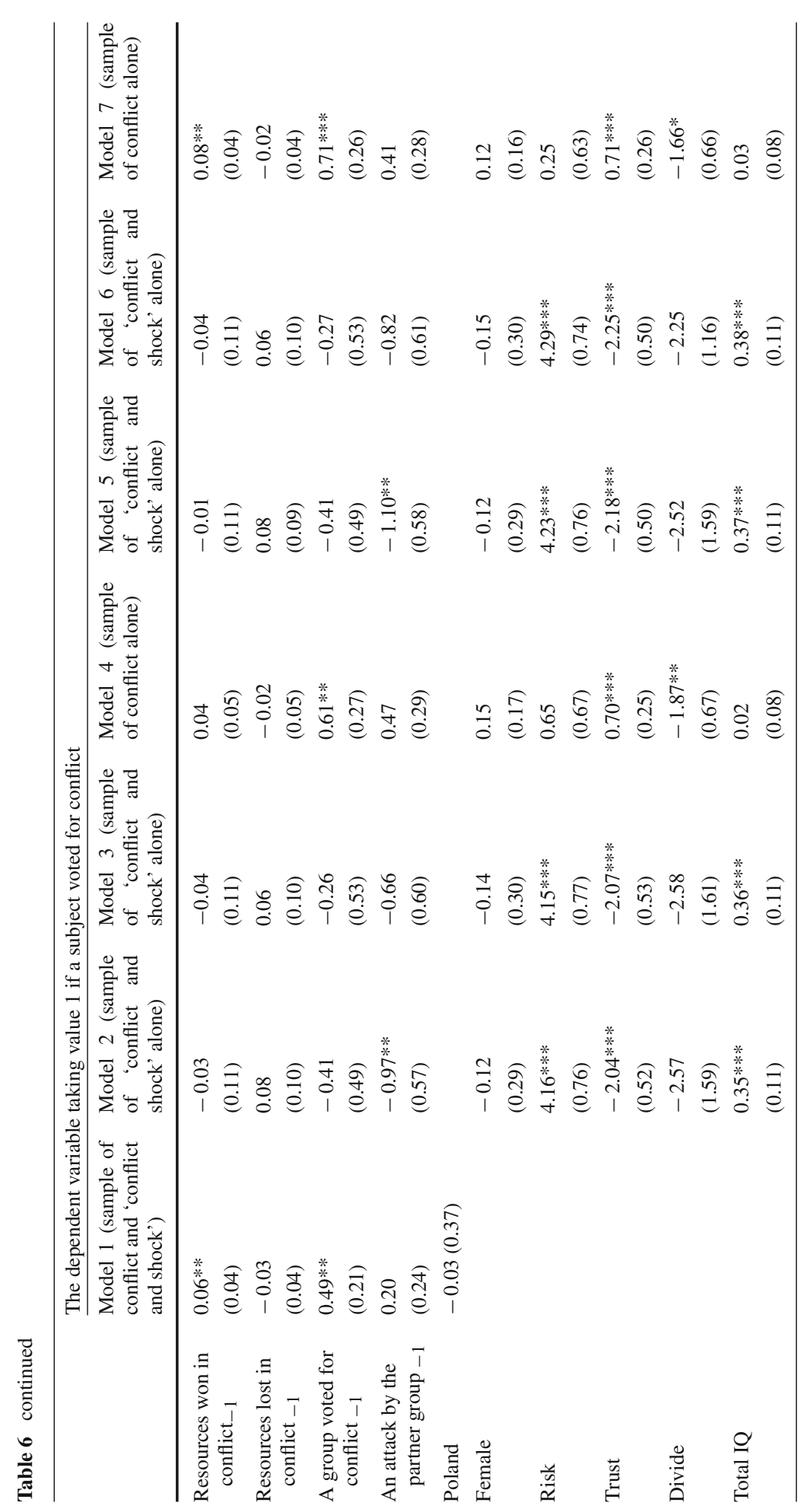




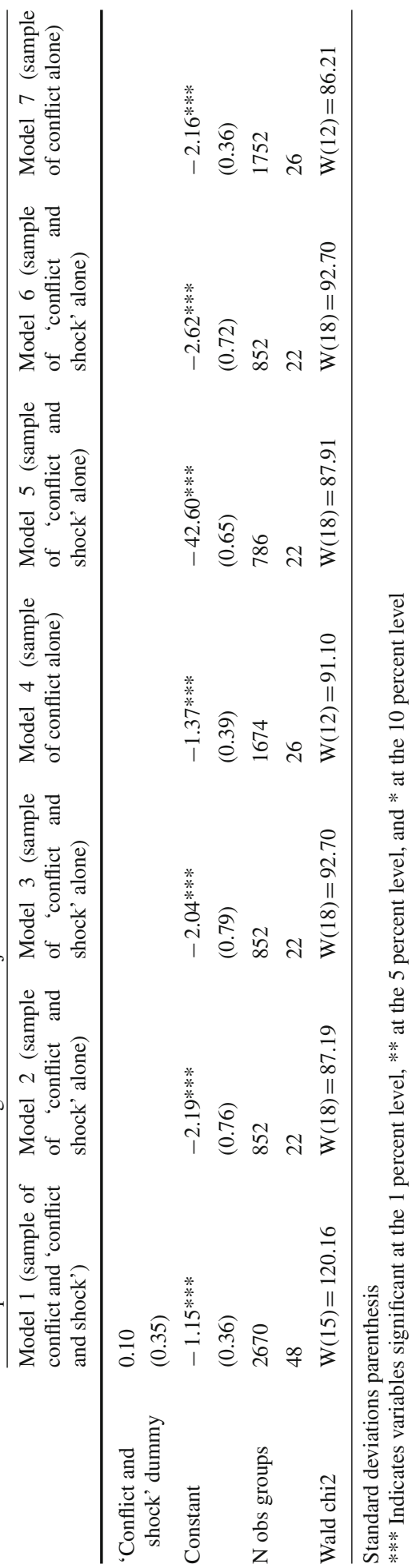

\section{照 Springer}




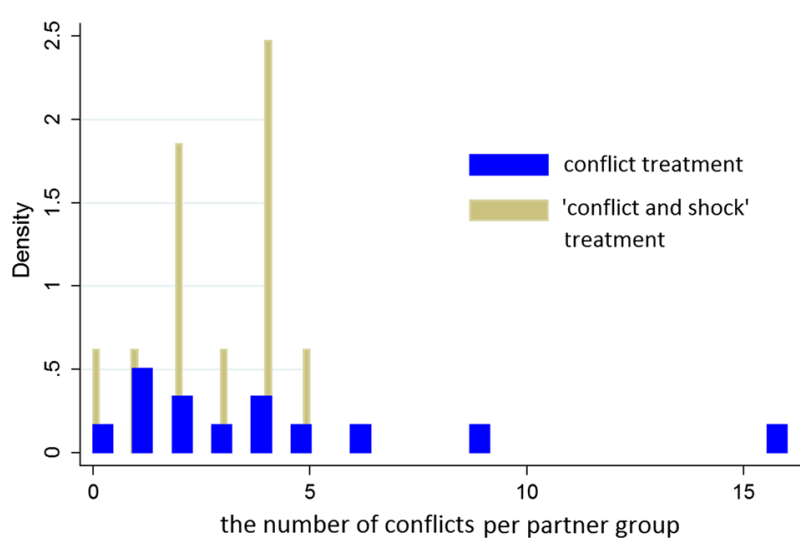

Fig. 3 The frequency distribution of the number of conflicts per partner group

destroyed by a shock in the current round, thus just before voting on conflict. In particular, the larger the fraction of partner group's resources destroyed by a shock in the current round has a negative impact on the probability of conflict. This effect is statistically significant in Model 3, but not in Model 6.

Result 5 In general, factors that improve the chances of winning increase the likelihood that a group attacks its partner. In the conflict treatment, conflict shows the signs of inertia. In particular, subjects are more likely to vote for conflict if the group won resources, or if it initiated conflict, in the past.

In all models in Table 6, the positive difference between own and partner group's resources has a positive and statistically significant impact on the probability that a subject would vote for conflict. This indicates that groups opt for conflict if they face a higher probability of winning. In turn, having less resources than the partner group is insignificant in explaining the probability of conflict, indicating that resource scarcity does not trigger conflicts in our experiment.

The results from Models 1, 4 and 8 in Table 6 reveal that in the conflict treatment, consecutive conflicts are self-amplifying: groups, which won resources in the past, improve their chances of future victories by increasing their own resources relative to the partner's resources, and are more likely to vote for conflict in subsequent rounds. In favor of this, variables indicating if a group voted for conflict, or won resources, in the previous round are statistically significant predictors that subjects would vote for conflict in the conflict treatment (Models 1, 4 and 8). These variables have no statistically significant impact on the probability of conflict in the sample of data from the 'conflict and shock' treatment alone.

Interestingly, resources lost in conflict have an insignificant impact on the probability of subjects voting for conflict in all regressions. The evidence in Table 6 indicates that subjects opt for conflict only if they believe that odds are on their side. The probability of winning increases with larger relative resources, or after annexing land from the partner group. In turn, factors, which reduce chances of winning, such as: having less resources than the partner group or loosing resources in conflict, do not affect subjects' reference behavior, which can be thought of as refraining from conflict.

Result 6 In the 'conflict and shock' treatment, conflict leads to moral hazard: subjects vote for conflict if they extract more for themselves so as to compensate for their risky behavior (overharvesting) by taking resources from the out-group. 
There is an important difference in factors conducive to conflict in the presence and absence of shocks. In the conflict treatment, subjects, who harvested less resources over time, are more likely to vote for conflict. As a result, groups, which conserve resources and face a higher probability of winning, are also more likely to engage in conflict. In favor of this, payoffs accumulated until time t have a negative and statistically significant impact on the probability of conflict (Models 1 and 4). This variable is insignificant in the "conflict and shock' treatment (Models 2 and 3).

Instead, in the 'conflict and shock' treatment, conflict is more likely, the more individuals harvest for themselves in the previous round. Formally, the variable fraction of harvested resources at time t has a positive and statistically significant impact on the probability of conflict in the 'conflict and shock' treatment (Models 5 and 6), but not in the conflict treatment (Model 7). This suggests that a combination of shocks and conflict leads to moral hazard, where subjects try to compensate for their risky behavior (overharvesting) by trying to take resources from the out-group. In addition, we find that subjects, who show more risk-seeking behavior in the pre-experimental questionnaire, are more likely to vote for conflict in the 'conflict and shock' treatment. In the absence of shocks, risk is statistically insignificant in explaining the probability of conflict (Model 4 in Table 6).

\section{Conclusion and Discussion of Results}

Climate change is expected to increase the frequency of natural disasters in the forthcoming years, putting natural resources at risk of their depletion. In particular, Africa is vulnerable to climate change, because of the continent's climatic, economic and political factors. So far, the literature on CPRs has paid little attention to between-group interactions and conflicts over resources. To fill in this gap, in this paper, we have presented an experimental design that begins to explore the role of intergroup conflict in the CPRs. In the experiment, subjects were asked to harvest resources repeatedly from the common pool of the renewable resource. Groups were matched in pairs at the beginning of each session. Subjects could observe harvesting decisions of members of their own group as well as members of the partner group. In this context, we examined how harvesting from the common-pool of resources was affected by (1) resource uncertainty, i.e. random shocks that could destroy part of resources; (2) and intergroup conflict.

Our results support the hypothesis that an uncertain danger of sudden resource depletion encourages resource conservation. This can be explained by the fact that random shocks destroying the resource decrease the probability that the game will continue to the next round. Only by conserving resources could subjects prevent resource exhaustion in the presence of shocks. This finding contradicts results from previous studies introducing uncertainty to CPR and environmental public good games. In particular, experiments by Rapoport et al. (1993) show that resource uncertainty undermines within-group cooperation. The important difference in our design, distinguishing it from previous studies, concerns the fact that in our experiment resources are renewable. As a result, subjects' decisions how much to extract today affect not only current payoffs, but also the availability of resources, and the probability of resource exhaustion in the future. In turn, in previous studies, the availability of the resource has been independent of past harvesting decisions. In our design, the fact that resources are renewable aligns the fate of group members and promotes cooperation.

We examine how conflicts unfold over time in CPRs. In the preceding studies on contest games, groups compete for a prize, where conflict is exogenously imposed on them. On the 
contrary, in our experiment, subjects decide if they would like to attack another group. In general, factors that improve the chances of winning increase the likelihood that a group attacks its partner. In particular, groups more affluent in resources, or which won resources in the past, are more likely to initiate conflicts. In addition, a group is more likely to be attacked if a larger fraction of its resource was destroyed by shocks in the past rounds. A shock improves the chances of the aggressor to win by increasing the difference in resources between groups. We find also that in $33 \%$ of conflicts, groups engage in conflict frequently, with one group attacking the partner group repeatedly until its collapse. This is surprising as groups voted for conflict in the 'destructive scenario' even if the resource in the partner group was on the verge of collapse, and thus the potential gain from conflict was negligible. This finding can be explained by subjects getting non-monetary benefits from engaging in conflict, or by "the pleasure of being nasty". Abbink and Sadrieh (2009) show that even without fear of retaliation, in a game where two players decide simultaneously on how much of the other players' endowment to destroy, money is destroyed in $40 \%$ of all decisions.

Our design allows us to examine how the possibility of conflict affects in-group behavior. In our experiment, the probability of winning in conflict is proportional to the difference in resources between groups. As a result, cooperation (resource conservation) increases groups' chances of winning in conflict. The evidence from the contest experiments have shown that group competition leads to higher level of cooperation and lower levels of free-riding (Bornstein and Erev 1994; Gunnthorsdottir and Rapoport 2006; Abbink et al. 2010). However, it is difficult to say if participants contributed more under group competition to CPRs because they believed this would make them more money, or because they wanted to contribute to the group's success irrespective of financial incentives (Burton-Chellew et al. 2010). Our results shed some light on this question, suggesting that cooperation is mostly driven by financial motives. We do not find support for the hypothesis that subjects reduce their harvests so as to increase their chances of winning in conflict. The possibility of conflict in itself does not affect extraction in our experiment. Instead, we find that intragroup cooperation depends on the outcomes of past conflicts. Subjects reduce their harvests only after experiencing a loss of resources, so as to restore the replenished stock and prevent the game to come to an end. If a group wins in conflict, group members reward themselves by harvesting more. The latter effect dominates the former, i.e. the coefficient corresponding to annexed resources is larger than the coefficient corresponding to resources lost in conflict in all regressions conducted at the individual level.

Finally, our results reveal a dark side of conflict under uncertainty: it undermines within group cooperation and leads to moral hazard. In particular, we find that in the presence of random shocks destroying resources, the positive impact of shocks on resource conservation disappears. Subjects harvest a significantly larger fraction of resources in the 'conflict and shock' treatment compared to the baseline and shock treatments. As a result, the probability of resource exhaustion is the highest here. This may be explained by the fact that subjects may perceive conflict as some type of insurance against shocks (O'Hare et al. 2015). Instead of reducing harvests to prevent resource exhaustion in the presence of shocks, subject try to compensate for overharvesting by taking resources from the out-group. In favor of this, in the 'conflict and shock' treatment, subjects, who overharvest resources, are more likely to vote for conflict.

Clearly more work is necessary to examine effects of conflict and climate change in CPRs. Our study raises many questions on how to avoid conflict and to prevent instances of repetitious destructive attacks, especially under resource uncertainty and different payoffs structures. The design of our experiment leads to conflict-by-strength, as the difference in resources determines the probability of winning in favor of groups relatively abundant in 
resources. Examining conflicts-for-need, for instance by assuming an exogenous a 50:50 probability of winning, could reveal different determinants of conflict, which constitutes an important topic for future research. Creating controlled sets of conditions in the laboratory setting can help to study the role of different incentives and institutions in mitigating conflicts.

Acknowledgements We would like to thank Rupert Sausgruber and James Tremewan for their helpful comments and suggestions. Pablo Torija and Marta Dyrkacz provided technical assistance. The research was supported by National Science Center Grant UMO-2013/08/S/HS4/00254.

Open Access This article is distributed under the terms of the Creative Commons Attribution 4.0 International License (http://creativecommons.org/licenses/by/4.0/), which permits unrestricted use, distribution, and reproduction in any medium, provided you give appropriate credit to the original author(s) and the source, provide a link to the Creative Commons license, and indicate if changes were made.

\section{References}

Abbink K, Sadrieh A (2009) The pleasure of being nasty. Econ Lett 105:306-308

Abbink R, Brandts J, Herrmann B, Orzen H (2010) Intergroup conflict and intra-group punishment in an experimental contest game. Am Econ Rev 100:420

Abbink K, Brandts J, Herrmann B, Orzen H (2012) Parochial altruism in inter-group conflicts. Econ Lett $117: 45-48$

Aflaki S (2013) The effect of environmental uncertainty on the tragedy of commons. Games Econ Behav $82: 240-254$

Antoniadou E, Koulovatianos C, Mirman LJ (2013) Strategic exploitation of a common-property resource under uncertainty. J Environ Econ Manag 65:28-39

Ashton J (2002) Avoiding conflicts over Africa's water resources. Ambio 31:236

Biel A, Grling T (1995) The role of uncertainty in resource dilemmas. J Environ Psychol 15:221-233

Blanco E, Lopez MC, Villamayor-Tomas S (2015) Exogenous degradation in the commons: field experimental evidence. Ecol Econ 120:430-439

Blanco E, Haller T, Lopez MC, Walker JM (2016a) The tension between private benefits and degradations from appropriation in the commons. J Econ Behav Organ 125:136-147

Blanco E, Lopez MC, Walker JM (2016b) The opportunity costs of conservation with deterministic and probabilistic degradation externalities. Environ Resour Econ 64:255

Bornstein G (2003) Intergroup conflict, individual, group and collective interest. Personal Soc Psychol Rev 7:129-145

Bornstein G, Erev I (1994) The enhancing effect of intergroup competition on group-performance. Int J Confl Manag 5:271-283

Botelho A, Dinar A, Pinto LM, Rapoport A (2014) Time and uncertainty in resource dilemmas: equilibrium solutions and experimental results. Exp Econ 17:649-672

Budescu DV, Rapoport A, Suleiman R (1992) Simultaneous versus sequential request in resource dilemmas with incomplete information. Acta Psychol 80:297-310

Budescu DV, Rapoport A, Suleiman R (1995) Common pool resource dilemmas under uncertainty: qualitative tests of equilibrium solutions. Games Econ Behav 10:171-201

Burton-Chellew M, Ross-Gillespie A, West S (2010) Cooperation in humans: competition between groups and proximate emotions. Evol Hum Behav 31:104-108

Cardenas J, Mantilla C (2015) Between-group competition, intra-group cooperation and relative performance. Front Behav Neurosci 33:1-9

Choi J-K, Bowles S (2007) The coevolution of parochial altruism and war. Science 318:636-640

Collier P, Hoeffler A (2004) Greed and grievance in civil war. Oxf Econ Pap 56:563-595

de Koning R (2007) Greed of grievance in West Africa's forest wars. In: de Jong W, Donovan D, Abe K (eds) Extreme conflicts and tropical forest. Springer, Dordrecht, pp 37-56

Dickinson D (1998) The voluntary contribution mechanism with uncertain group payoffs. J Econ Behav Organ 35:517-533

Downing AS et al (2014) Coupled human and natural system dynamics as key to the sustainability of Lake Victoria's ecosystem services. Ecol Soc 19:31

Ember CR, Ember M (1992) Resource unpredictability, mistrust, and war: a cross-cultural study. J Confl Resolut 36:242 
Falk A, Fehr E, Fischbacher U (2002) Appropriating the commons: a theoretical explanation. In: Dietz R, Dolsak N, Ostrom E, Stern P, Stonich S, Weber E (eds) The drama of the commons. National Academy Press, Washington, pp 157-192

FAO (2005) State of the world's forests 2005. Food and Agricultural Organization of the United Nations, Rome

Fischbacher U (2007) Z-Tree: Zurich toolbox for ready-made economic experiments. Exp Econ 10:171-178

Gangadharan L, Nemes V (2009) Experimental analysis of risk and uncertainty in provisioning private and public goods. Econ Inq 47:146-164

Garfinkel MR, Skaperdas S (2007) Economics of conflict: an overview. In: Sandler T, Hartley K (eds) Handbook of defense economics, vol 2. Elsevier, New York, pp 649-709

Gneezy U, Potters J (1997) An experiment on risk taking and evaluation periods. Q J Econ 112:631-645

Gunnthorsdottir A, Rapoport A (2006) Embedding social dilemmas in intergroup competition reduces freeriding. Organ Behav Hum Decis Process 101:184-199

Harari M, La Ferrara E (2017) Conflict, climate and cells: a disaggregated analysis. Forthcoming in Review of Economics and Statistics

Hardin G (1968) The tragedy of commons. Science 162:1243-1248

Hine D, Gifford R (1996) Individual restraint and group efficiency in commons dilemmas: the effects of two types of environmental uncertainty. J Appl Soc Psychol 26:993-1009

Homer-Dixon TF (1994) Environmental scarcities and violent conflicts: evidence from cases. Int Secur 19:5-40

Homer-Dixon TF (1999) Environmental, scarcity, violence. Princeton University Press

Hsiang SM, Burke M, Miguel E (2013) Quantifying the influence of climate on human conflict. Science $341: 1235367$

IPCC (2007) Fourth Assessment Report. The united Nations Intergovernmental Panel on Climate Change

Janssen MA (2010) Introducing ecological dynamics into common-pool resource experiments. Ecol Soc 15(2):7

Janssen MA, Holahan R, Lee A, Ostrom E (2011) Lab experiments for the study of social-ecological systems. Science 328:613-617

Kimbrough E, Wilson BJ (2013) Insiders, outsiders, and the adaptability of informal rules to ecological shocks. Ecol Econ 90:29-40

Mildner S-A, Lauster g, Wodni W (2011) Scarcity and abundance revised: a literature review on natural resources and conflict. Int J Confl Violence 5:155-172

Mwiturubani DA (2010) Climate change and access to natural resources. In: van Wyk JA, Mwiturubani A (eds) Climate change and natural resources conflicts in Africa. Institute for Security Studies, Pretoria, pp 63-80

Nillesen E, Bulte E (2014) Natural resources and violent conflict. Ann Rev Resour Econ 6:69-83

O'Hare P, White I, Connelly A (2015) Insurance as maladaptation: resilience and the 'business as usual' paradox. Environmental and Planning C Government and Policy , pp 1-19

Ostrom E (1992) Covenants with and without a sword: self-governance is possible. Am Pol Sci Rev 86:404

Ostrom E (2006) The value-added of laboratory experiments for the study of institutions and common-pool resources. J Econ Behav Organ 61:149

Ostrom E et al (1994) Rules, games, and common-pool resources. University of Michigan Press, Ann Arbor

Pomeroy R, Parks J, Pollnac R, Campson T, Genio E, Marlessy C, Holle E, Pido M, Nissapa A, Boromthanara S, Thu Hue N (2007) Fish wars: conflict and collaboration in fisheries management in Southeast Asia. Mar Policy 31:6450656

Rapoport A, Bornstein G (1987) Intergroup competition for the provision of binary public goods. Psychol Rev 3:291-299

Rapoport A, Budescu DV, Suleiman R (1993) Sequential requests from randomly distributed shared resources. J Math Psychol 37:241-241

Safarzynska K (2013) The coevolution of culture and environment. J Theor Biol 322:46

Schleussner C-F, Donges JF, Donner RV, Schellnhuber HJ (2016) Armed-conflict risks encahnces by climaterelated distasters in ethnically fractionalized countries. PNAS 113:9216-9221

Sheremeta RM (2017) Behavior in group contest: a review of experimental research. J Econ Surv 0:1-22

Sigmund K, De Silve H, Traulsen A, Hauert C (2010) Social learning promotes institutions for governing the commons. Nature 466:1038

USAID (2005) Forests \&conflict. A toolkit for intervention. Washington, DC: Office of Conflict Management and Mitigation, Bureau for Democracy, Conflict and Humanitarian Assistance, U.S. Agency for International Development. Available from

Walker JM, Gardner R (1992) Probabilistic destruction of common-pool resources: experimental evidence. Econ J 102:1149-1161 